\title{
Anti-Urolithiatic Activity of Melia Azedarach Linn Leaf Extract in Ethylene Glycol-Induced Urolithiasis in Male Albino Rats
}

\author{
Senthil Rajan Dharmalingam', Rajkumar Madhappan², Kumarappan \\ Chidambaram ${ }^{1}$, Srinivasan Ramamurthy ${ }^{1}$, Krishna Gopal ${ }^{2}, \mathrm{P}$ Swetha ${ }^{2}$ and KL \\ Senthil Kumar ${ }^{2}$ \\ ${ }^{1}$ School of Pharmacy, International Medical University, Kuala Lumpur, Malaysia \\ ${ }^{2}$ Department of Pharmacognosy, Padmavathi College of Pharmacy and Research Institute, Tamilnadu, India.
}

*For correspondence: Email: dsenthilrajan@yahoo.co.ini Tel: +60 327317310.

\begin{abstract}
Purpose: To investigate the anti-urolithiatic activity of the aqueous and alcoholic extracts of Melia azedarach Linn leaves in calcium oxalate urolithiasis in male albino rats.

Methods: The effect of oral administration of aqueous and ethanol extracts of Melia azedarach Linn leaves on calcium oxalate urolithiasis has been investigated. Lithiasis was induced by oral adminstration of ethylene glycol $(0.75 \% \mathrm{v} / \mathrm{v})$ in male albino rats for 28 days. Each of the extract $(250 \mathrm{mg} / \mathrm{kg})$ was administered orally day 0 as a prophylactic regimen and from day 15 as a curative regimen. Regular administration of ethylene glycol caused hyperoxaluria in ethylene glycol-fed animals, leading to increased renal retention and excretion of oxalate, calcium and phosphate. Histopathological study, urine microscopy, serum analysis and biochemical analysis of kidney homogenate were performed. Results: Oxalate and calcium excretion in urine increased $(p<0.01)$ to $3.68 \pm 0.01$ and $4.5 \pm 0.01$ $\mathrm{mg} / 24 \mathrm{~h}$, respectively, in lithiatic control animals compared to $(0.37 \pm 0.01$ and $1.27 \pm 0.12 \mathrm{mg} / 24 \mathrm{~h}$ ) for the normal control group. Treatment with aqueous or ethanol extract $(250 \mathrm{mg} / \mathrm{kg}, \mathrm{p}$.o.) significantly $(p<$ 0.01 ) reduced the elevated levels of calcium, oxalate and phosphate excretion in urine to $0.79 \pm 0.01$ and $1.09 \pm 0.04 \mathrm{mg} / 24 \mathrm{~h}$, respectively. Following treatment with the ethanol extract $(250 \mathrm{mg} / \mathrm{kg})$, serum creatinine excretion was restored from $0.95 \pm 0.01 \mathrm{mg} / 24 \mathrm{~h}$ to the normal level of $0.87 \pm 0.01 \mathrm{mg} / 24 \mathrm{~h}$. The results were comparable to those of the standard drug, allopurinol (50 mg/kg p.o.). Histopathological data for the kidney supported the foregoing results.

Conclusions: The results demonstrate that the aqueous and ethanol extracts of Melia azedarach Linn leaves have potent antiurolithiatic activity against ethylene glycol-induced calcium oxalate urolithiasis in male albino rats.
\end{abstract}

Keywords: Melia azedarach, Antiurolithiatic, Ethylene glycol, Urolithiasis, Excretion, Kidney.

Tropical Journal of Pharmaceutical Research is indexed by Science Citation Index (SciSearch), Scopus, International Pharmaceutical Abstract, Chemical Abstracts, Embase, Index Copernicus, EBSCO, African Index Medicus, JournalSeek, Journal Citation Reports/Science Edition, Directory of Open Access Journals (DOAJ), African Journal Online, Bioline International, Open-J-Gate and Pharmacy Abstracts

\section{INTRODUCTION}

Urinary calculi are the third prevalent disorder in the urinary system. It is calculated that nearly $10 \%$ of the population of the industrialized world is affected by urinary tract stone disease. Kidney stones account for 0.5 to $1.9 \%$ of clinical cases in industrialized countries [1]. Urinary calculi may cause obstruction, hydronephrosis, infection and hemorrhage in the urinary tract system [2]. Since the mid-1980s, management of nephrolithiasis has been by non-surgical methods such as lithotripsy, fiberoptic technology, electrical sparks and laser techniques, which provide therapeutic 
alternatives to surgery. Thus, the requirement for surgical intervention for removal of kidney stones has almost been reduced. Although, these procedures are cost-effective, they have side effects and may cause severe complications. Many Indian plants are thought to be useful antiurolithiatic agents [2,3]. Hence, plants are sometimes evaluated for possible antilithiatic.

Melia azedarach Linn (meliaceae) popularly known as media dubia Cav, Indian lilac and Persian lilac, is found in most of the tropical and sub-tropical countries, including India, China, Japan .Philippines, Brazil, Argentina, as well as African and Arab countries, and the United States of America [4]. Chemical constituents of the leaves include nimbinene, quercetin-3-0-brutinoside, kaempferol- 3-0-b rutinoside, rutin and kaempferol-3-L-rhamno-Dglucoside, nimbinene, azaridine, meliacin and quercetin [5,6]. A literature survey revealed that $M$. azedarach Linn also contains glycerol 1, 3-bisundec- 9- enoate 2dodec-9-enoate and glycerol tris-tridec-9-enoate, dipentadecyl ketone, flavonoids, limmonoids, tannis, sterols, saponines and triterpenoids which possibly contribute to its various uses in tradition medicine $[7,8]$.

The present investigation was designed to evaluate the anti-urolithiatic property of the aqueous and ethanol extract of Melia azedarach Linn leaves in ethylene glycol-induced calcium oxalate urolithiasis in male albino rats.

\section{EXPERIMENTAL}

\section{Collection of plant material}

The leaves of Melia azedarach were collected from the botanical garden at the Campus of Padmavathi College of Pharmacy, Dharmapuri in June, 2011. The plant was identified and authenticated by Dr. P. Jayaraman, Botanist, Director of Plant Anatomy Research Centre (PARC), Chennai, India. A voucher specimen (PARC /2011/2831) was deposited at the Padmavathi herbarium of the Centre for future reference.

\section{Preparation of aqueous extract}

The shade-dried leaves were pulverized to a coarse powder which was used for extraction. The aqueous extract was prepared according to a previous method [9]. Briefly, $100 \mathrm{~g}$ of the powdered leaves was mixed with $500 \mathrm{~mL}$ of distilled water in a $1 \mathrm{~L}$ flask and boiled for $1 \frac{1}{2} \mathrm{~h}$. The extract was filtered using whatman No.1 filter paper after cooling it to $40^{\circ} \mathrm{C}$. The filtrate was concentrated in a rotary evaporator under vacuum $\left(40{ }^{\circ} \mathrm{C}\right)$ and stored at $4{ }^{\circ} \mathrm{C}$ until used. The yield was $8.23 \% \mathrm{w} / \mathrm{w}$.

\section{Preparation of ethanol extract}

Crude ethanolic extract of powered plants was prepared according to a previous method [10] in which $200 \mathrm{~g}$ of ground plant material was soaked in $500 \mathrm{ml}$ of $70 \%$ aqueous ethanol by cold maceration at room temperature for $72 \mathrm{~h}$, after which the filtrate was collected through a piece of muslin cloth and then filter paper; the marc was subjected to the same procedure twice. The filtrate was concentrated in a rotary evaporator at $40{ }^{\circ} \mathrm{C}$ under reduced pressure to yield the crude extract. This extract was stored at $4{ }^{\circ} \mathrm{C}$ pending its use. The yield of the extract was $8.84 \% \mathrm{w} / \mathrm{w}$. The aqueous and alcohol extracts were subjected to preliminary phytochemical analyses using standard methods [11].

\section{Experimental animals}

Male albino rats weighing 150 - $200 \mathrm{~g}$ were used. The animals were fed standardized animal chow and water ad libitum. The rats were used after acclimatization under controlled conditions of temperature of $24 \pm 2{ }^{\circ} \mathrm{C}$, humidity of $50 \pm 5 \%$ and $10-12 \mathrm{~h}$ of light and dark cycles for one week. The animals were housed individually in metabolic cages containing sterile paddy husk as bedding throughout the experiment. The toxicity and anti-urolithic experimental studies were conducted after obtaining the approval of the institutional Animal Ethical Committee, Padmavathi College of Pharmacy (approval ref. no IECA/CBCSEA/2012/093). Animal experiments were performed in accordance with the guide for the humane care and use of laboratory animals [11] and CPCSEA guidelines of the Government of India.

\section{Acute toxicity studies}

Male albino rats were used for studies. The animal were fasted overnight, providing them with only water. Acute oral toxicity study was performed using both the aqueous and ethanol extracts (based on OECD guidelines) at dose range 250 to $2500 \mathrm{mg} / \mathrm{kg}$ [12]. If mortality was observed in two out of three animals, than the dose administered was assigned as toxic dose. If the mortality was observed in one animal, than the same dose was repeated again, and if mortality was not observed, the procedure was repeated for the higher dose, up to $2500 \mathrm{mg} / \mathrm{kg}$. The animals were observed for body temperature, behavioral, neurological and autonomic profiles for $24 \mathrm{~h}$ [13]. 


\section{Animal studies}

The animals were divided into seven groups of 6 animals each. Group I served as normal control and received regular rat feed and drinking water ad libitum. Ethylene glycol $(0.75 \%)$ in drinking water was fed to Groups II - VII for induction of renal calculi for 28 days. Group II served as lithiatic control and received vehicle (1\% Tween $80)$; Group III received the standard antiurolithiatic drug, allopurinol (50 mg/kg bw, po) from the 15th to 28th day. Group IV received the aqueous extract $(250 \mathrm{mg} / \mathrm{kg}$ bw, po.) from the 15th day till 28th day and served as curative regimen $(\mathrm{CR})$. Group $\mathrm{V}$ received the ethanolic extract $(250 \mathrm{mg} / \mathrm{kg} \mathrm{bw}$, po.) from 1st day till 28th day and served as CR. Group VI received the aqueous extract (250 mg/kg, p.o.) from the 15th to 28th day and served as preventive regimen (PR). Group VII received the ethanol extract (250 $\mathrm{mg} / \mathrm{kg}$, p.o.) from the $1 \mathrm{st}$ to 28 th day and also served as PR. All the drugs were given once daily by oral route using gastric tube.

\section{Urine analysis}

The rats were kept separately in metabolic cages and $24 \mathrm{~h}$ urine samples were collected on the 28th day. A drop of concentrated hydrochloric acid was added to the urine prior to storage at 4 ${ }^{\circ} \mathrm{C}$, and then analysed for calcium and oxalate content by colorimetric procedure [14] and for phosphorus content by molybdenum blue reaction [15]. The collected urine samples were centrifuged at $3000 \mathrm{rpm}$ for $10 \mathrm{~min}$. After centrifugation, the urine samples were examined under light microscope to ensure the frequency, shape and size of the calcium oxalate crystals

\section{Serum analysis}

At the end of the treatment period, the animals were sacrificed by cervical dislocation under anaesthetia and blood was collected from the retro-orbital puncture of animal. Serum was separated by centrifugation at $10,000 \mathrm{~g}$ for 10 min analyzed for creatinine and urea nitrogen content using commercially available kits and uric acid by a colorimetric method [16].

\section{Histopathology}

Three animals in each group were sacrificed at the end of the final urine collection. The kidneys were washed, weighed and fixed rapidly with 10 $\%$ neutralized formalin ( $\mathrm{pH} 7.4$ ), embedded in paraffin, sliced $5 \mu \mathrm{m}$ pieces; the slices were stained with hematoxylin and eosin and mounted in diphenyl xylene. Tissue slices were photographed using optical microscopy and the histopathological changes in kidney architecture observed [17].

\section{Biochemical analysis of kidney homogenate}

Isolated kidneys were dried at $80{ }^{\circ} \mathrm{C}$ in a hot air oven. A sample of $100 \mathrm{mg}$ of the dried kidney was boiled in $10 \mathrm{ml}$ of $1 \mathrm{M}$ hydrochloric acid for $30 \mathrm{~min}$ and homogenized. The homogenate was centrifuged at $2000 \mathrm{~g}$ for $10 \mathrm{~min}$ and the supernatant separated. The supernatant was analysed for calcium and oxalate content by a colorimetric procedure [14] as well as for phosphorus content in the kidney homogenate by molybdenum blue reaction [18].

\section{Statistical analysis}

The data obtained were expressed as mean \pm SD and analysed for differences using one-way ANOVA followed by Dunnet multiple comparison test using Graph Pad Prism software (GraphPad Software Inc, version 4.0.0.255).

\section{RESULTS}

The preliminary phytochemical study of Melia azedarach showed the presence of flavonoids and saponins in aqueous extract and alkaloids, carbohydrates, glycosides, saponins, steroids and triterpenoids in the ethanol extract of Melia azedarach leaves.

\section{Acute toxicity}

The extract showed neither mortality nor any visible clinical signs of general weakness in the animals. Hence, $2500 \mathrm{mg} / \mathrm{kg}$ was considered as $L_{50}$ cut-off value and $250 \mathrm{mg} / \mathrm{kg}$ (1/10 of 2500 $\mathrm{mg} / \mathrm{kg}$ ) was taken as treatment dose based on the fixed-dose method of OECD guidelines.

\section{Anti-urolithiatic activity}

Chronic administration of ethylene glycol (0.75 $\%$ ) in aqueous solution to the rats resulted in hyperoxaluria. Oxalate and calcium excretion in urine increased to $3.68 \pm 0.01$ and $4.50 \pm 0.01$ $\mathrm{mg} / 24 \mathrm{~h}$ respectively in calculi-induced animals compared to normal control group (Table 1, Group II).

However, administration of ethanol extract and aqueous extracts significantly $(p<0.01)$ reduced the elevated levels of calcium, oxalate, phosphate excretion in urine to $0.79 \pm 0.01$ and $1.09 \pm 0.04 \mathrm{mg} / 24 \mathrm{~h}$, respectively (Table 1 , Groups IV - VII). 
Table 1: Urinary excretion of kidney stone-forming constituents in experimental rats treated with Melia azedarach extracts $(n=6)$

\begin{tabular}{lllll}
\hline \multirow{2}{*}{ Group } & $\begin{array}{l}\text { Dose } \\
(\mathbf{m g} / \mathbf{k g})\end{array}$ & \multicolumn{2}{l}{ Urine parameter $(\mathrm{mg} / 24 \mathrm{~h}, \mathrm{mean} \pm \mathrm{SEM})$} \\
\cline { 3 - 5 } & Vehicle & $0.37 \pm 0.01$ & $1.266 \pm 0.12$ & $3.64 \pm 0.01$ \\
\hline I : Normal control & Vehicle & $3.68 \pm 0.01$ & $4.50 \pm 0.01$ & $7.28 \pm 0.01$ \\
II : Lithiatic control & 50 & $0.53 \pm 0.02^{*}$ & $1.49 \pm 0.01^{*}$ & $3.80 \pm 0.01^{*}$ \\
III : Allopurinol & 250 & $0.89 \pm 0.01^{*}$ & $1.78 \pm 0.01^{*}$ & $4.05 \pm 0.03^{*}$ \\
IV : Ethanolic extract (CR) & 250 & $1.29 \pm 0.01^{*}$ & $1.90 \pm 0.02$ & $4.13 \pm 0.02^{*}$ \\
V : Aqueous extract (CR) & 250 & $0.79 \pm 0.01^{*}$ & $1.68 \pm 0.02^{*}$ & $3.98 \pm 0.02^{*}$ \\
VI : Ethanolic extract (PR) & 250 & $1.09 \pm 0.04^{*}$ & $1.87 \pm 0.02^{*}$ & $4.21 \pm 0.01^{*}$ \\
VII : Aqueous extract (PR) & & & Calcium & \\
\hline
\end{tabular}

${ }^{*} p<0.01$ (significant compared to lithiatic control); $n s=$ not significant

Table 2: Kidney stone-forming constituents in rats treated with Melia azedarach extracts $(n=6)$

\begin{tabular}{lllll}
\hline \multirow{2}{*}{ Group } & $\begin{array}{l}\text { Dose } \\
(\mathbf{m g} / \mathbf{k g})\end{array}$ & \multicolumn{2}{l}{ Kidney parameter $(\mathrm{mg} / \mathbf{g})$ (mean \pm SEM) } \\
\cline { 3 - 5 } & Oxalate & Calcium & Phosphate \\
\hline I : Normal control & Vehicle & $1.44 \pm 0.02^{* *}$ & $3.22 \pm 0.02^{* *}$ & $2.34 \pm 0.03^{* *}$ \\
II : Lithiatic control & Vehicle & $5.73 \pm 0.03$ & $4.77 \pm 0.02$ & $3.75 \pm 0.03$ \\
III : Allopurinol & 50 & $1.60 \pm 0.02^{* *}$ & $3.39 \pm 0.02^{* *}$ & $2.52 \pm 0.02^{* *}$ \\
IV : Ethanolic extract (CR) & 250 & $1.82 \pm 0.01^{* *}$ & $3.69 \pm 0.02^{* *}$ & $2.75 \pm 0.02^{* *}$ \\
V : Aqueous extract (CR) & 250 & $2.13 \pm 0.02^{* *}$ & $4.12 \pm 0.01$ & $2.91 \pm 0.02^{* *}$ \\
VI : Ethanolic extract (PR) & 250 & $1.76 \pm 0.01^{* *}$ & $3.59 \pm 0.04^{* *}$ & $2.67 \pm 0.01^{* *}$ \\
VII : Aqueous extract (PR) & 250 & $2.07 \pm 0.01^{* *}$ & $3.94 \pm 0.05$ & $2.85 \pm 0.02^{* *}$ \\
\hline
\end{tabular}

${ }^{* *} p<0.01$ (significant compared to lithiatic control); ns = not significant

Table 3: Serum parameters of rats treated with Melia azedarach extracts $(n=6)$

\begin{tabular}{|c|c|c|c|c|}
\hline \multirow[b]{2}{*}{ Group } & \multirow{2}{*}{$\begin{array}{l}\text { Dose } \\
\text { (mg/kg) }\end{array}$} & \multicolumn{2}{|c|}{ Serum parameter (mean \pm SEM) } & \multirow[b]{2}{*}{ Uric acid } \\
\hline & & $\begin{array}{l}\text { Blood urea } \\
\text { nitrogen }\end{array}$ & Creatinine & \\
\hline I: Normal control & Vehicle & $37.08 \pm 0.45$ & $0.76 \pm 0.02$ & $1.49 \pm 0.02$ \\
\hline II : Lithiatic control & Vehicle & $49.66 \pm 1.16$ & $0.95 \pm 0.01$ & $3.64 \pm 0.02$ \\
\hline III : Allopurinol & 50 & $39.58 \pm 1.10^{* *}$ & $0.81 \pm 0.01^{* *}$ & $1.71 \pm 0.01^{\mathrm{ns}}$ \\
\hline IV : Ethanolic extract (CR) & 250 & $40.53 \pm 1.19^{* *}$ & $0.84 \pm 0.01^{* *}$ & $1.90 \pm 0.01^{* *}$ \\
\hline V : Aqueous extract (CR) & 250 & $41.98 \pm 1.42^{* *}$ & $0.91 \pm 0.01^{\mathrm{ns}}$ & $2.12 \pm 0.01^{* *}$ \\
\hline VI : Ethanolic extract (PR) & 250 & $40.63 \pm 0.78^{* *}$ & $0.87 \pm 0.01^{* *}$ & $1.90 \pm 0.01^{* *}$ \\
\hline VII : Aqueous extract (PR) & 250 & $40.77 \pm 0.808^{* *}$ & $0.91 \pm 0.01^{\mathrm{ns}}$ & $2.03 \pm 0.04^{* *}$ \\
\hline
\end{tabular}

Administration of ethylene glycol $(0.75 \% \mathrm{v} / \mathrm{v})$ to male albino rats for 14 days forms renal calculi composed mainly of calcium oxalate (Group II). Deposition of the crystalline components in the homogenised renal tissue increased to $5.73 \pm$ $0.03 \mathrm{mg} / \mathrm{gm}$ in lithiatic control group (Table 2, Group II). Kidney homogenate results reveal that both ethanol and aqueous extracts at a dose of $250 \mathrm{mg} / \mathrm{kg}$ significantly $(p<0.01$ ) lowered the elevated levels of calcium, oxalate, phosphate excretion closer to normal (control) group values (Table 2, Groups IV - VII).

The creatinine clearance of lithiatic control rats were decreased, but it was improved in standard drug and extract-treated groups. Serum analysis showed a significant increase $(p<0.01)$ in creatinine levels in lithiatic control rats when compared to normal rats (Group I). After treatment with ethanol extract, serum creatinine 
levels were restored to the normal value of 0.87 $\pm 0.01 \mathrm{mg} / \mathrm{dl}$ (Table 3, Group Vl).

Urine microscopy analysis revealed frequency and size of calcium oxalate crystals is larger in the urine of lithiatic group animals (Fig 1B), when compared with control group (Fig 1A). On the other hand, the ethanol and aqueous extracttreated groups showed significant reduction in frequency and size of calcium oxalate crystals compared with lithiatic group (Fig $1 \mathrm{~F}$ and $1 \mathrm{G}$ ).

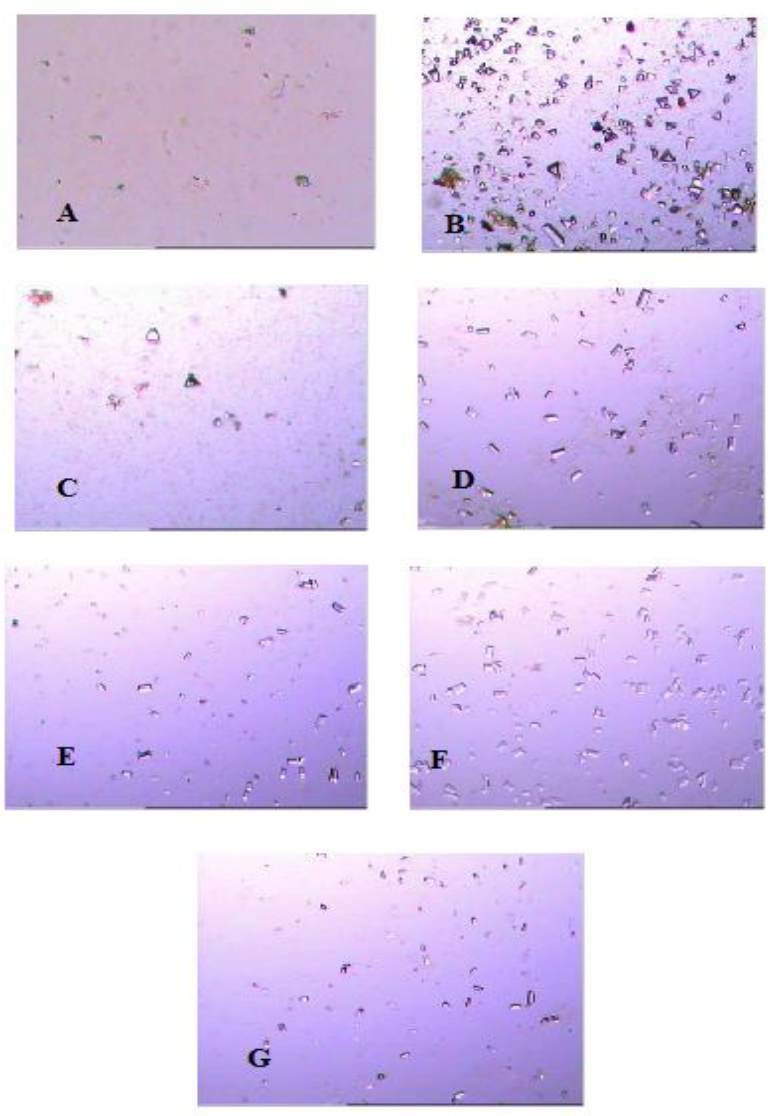

Fig 1: Urine microscopy photographs of aqueous and ethanol extract treated group. (A) normal group (control, untreated); (B) lithiatic control (untreated) group; (C) allopurinol-treated group; (D) aqueous extract-treated group (curative regimen); (E) ethanol extract-treated group (curative regimen); ( $F)$ aqueous extract-treated group (preventive regimen); and (G) ethanol extract-treated group (preventive regimen).

The histopathological study of the kidneys from the rats in the normal control group (Group 1), presented a normal appearance with normal glomeruli, proximal and distal convoluted tubules without any inflammatory changes, normal blood vessels and no calcium oxalate depositions (Figure. 2A). In lithiatic control, there was presence of small slender pointed calcium oxalate crystals in lumen of proximal convoluted tubule.
Tubules were highly dilated and cystic tubules with sloughing of the tubular epithelial cells (Figure 2B). There were irregular calcium oxalate crystals in the lamina of the tubules which caused dilation of proximal tubules along with interstitial inflammation.

The aqueous extract-treated animals showed few crystals as well as appearance of slight edema and dilation in tubules (Figure 2C). Similarly, in animals administered ethanol extract, no crystals were observed and apparently retained normal morphology, tubular epithelial cells and glomeruli as in control group (Figure 2D). However, very mild degeneration of cells and cyst formation were observed.
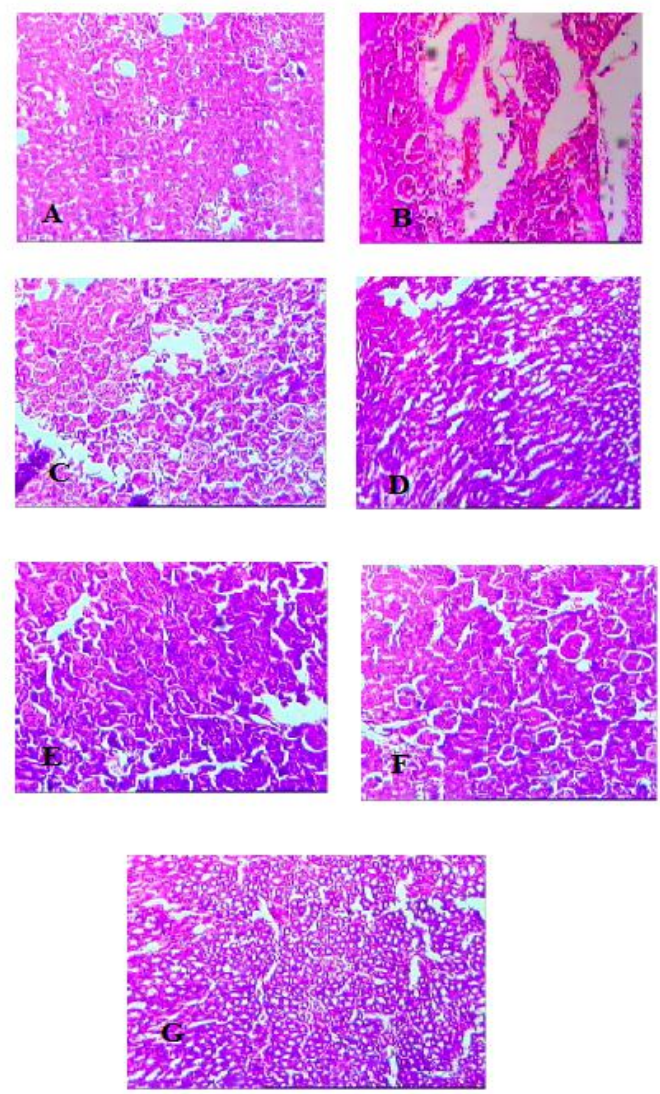

Fig 2: Kidney histopathology of photographs of aqueous and ethanol extract treated group. (A) normal group (untreated) (B) lithiatic control (untreated) group (C) allopurinol-treated group; ( D) aqueous extract-treated group (curative regimen); (E) ethanol-extract treated group (curative regimen); ( F) aqueous extract treated group (preventive regimen)and (G) ethanol extract-treated group (preventive regimen).

\section{DISCUSSION}

Increased urinary calcium is a factor favoring the nucleation and precipitation of calcium, oxalate or phosphate from urine and consequent crystal growth. It has been reported that 
hyperabsorption of calcium is due to defective renal tubular reabsorption [16]. Stone formation in ethylene glycol-fed animals is caused by hyperoxaluria, which causes increased renal retention and excretion of oxalate [17].

Evidence from earlier studies indicate that methylene glycol is metabolized to oxalate [20]. Enzymatic disturbances are causative factors of idiopathic hyperoxaluria, which causes increased renal retention and excretion of oxalate [18]. In this study, supplementation with ethanol extract of Melia azedarach, restored urinary phosphate level, thereby reducing the risk of stone formation and lower the levels of calcium as well as oxalate in urine.

The extracts hastened the process of dissolving the preformed stones in curative regimen and prevention of new stone formation in urinary system on prophylactic treatment, may be due to mild diuretic effect and antioxidant activity mild diuretic effect and antioxidant activity [22].

Similar histopathological observations, earlier reported support, the presence of glomerular atrophy and deposition of crystals and attainment of normalcy of tubular epithelial cells and glomeruli when treated with plant extract [5].

In lithiatic control rats (Group II), marked renal damage is evidenced by the elevated serum levels of creatinine, uric acid and blood urea nitrogen. The significant elevated serum levels of blood urea nitrogen, creatinine and uric acid in lithiatic control animals may be due to the obstruction of the outflow of the urine by stones in urinary system. However, ethanol and aqueous extractrestored the elevated serum levels of creatinine, uric acid and blood urea nitrogen, the markers previously reported which affirms the potent antiurolithiatic activity of the extracts [4]. These results indicate the presence of calcium oxalate crystal aggregation inhibitory constituent(s) in the plant that interfere with crystal growth and aggregation; this probably is a pointer to a possible therapeutic strategy for the prevention of recurrent stone disease.

The plant Melia azedarach extract have been reported to possess anti-inflammatory [23] and antimicrobial activities [24], and this may complement its beneficial effect in urolithiasis, as infection and inflammation are likely to be associated with urolithiasis process.

\section{CONCLUSION}

The findings of this study demonstrate that the aqueous and ethanol leaf extracts of Melia azedarach Linn possess potent antiurolithiatic activity against ethylene glycol-induced calcium oxalate urolithiasis in rats. The antiurolithiatic effects may be mediated possibly through a combination of calcium oxalate crystal inhibition, as well as via diuretic, antioxidant, renal epithelial cell protective, and hyper-magneseuric effects. Further investigation on its safety profile, antioxidant activity and diuretic effect is essential to establish its potential for clinical use.

\section{ACKNOWLEDGMENT}

The authors are thankful to Padmavathi College of Pharmacy and Research Institute, Tamil nadu, India for providing laboratory facilities to carry out this work.

\section{REFERENCES}

1. Pendse AK. Urolithiasis in Udaipur and Jodhpur: $A$ comparative study on prevalence and urinary profile. Bull III, Ann Conf Urol Soc India, 1985; 12.

2. Hadjzadeh MA, Khoei $A$, Hadjzadeh $Z$, and Parizady $M$. Ethanolic extract of Nigella sativa $L$. seeds on ethylene glycol-induced kidney calculi in rats. Urol J 2007; 4: 86-90.

3. Atmani F, Slimani Y, Mimouni M, Aziz M, Hacht B, Ziyyat A. Effect of aqueous extract from Herniaria hirsute $L$. on experimentally nephrolithiasic rats. $J$ Ethnopharmacol 2004; 95: 87-95.

4. Khan AV, Khan AA, Shukla I. In vitro antibacterial potential of Melia azedarach crude leaf extracts against some human pathogenic bacterial strains. Ethnobotanical Leaflets 2008; 12: 439-445.

5. Sharma PC, Yelne MB, Dennis T-J. Data Base on Medicinal Plants Used in Ayurveda. Central Council for Research in Ayurveda and Siddha, New Delhi, India 2001; 389-406.

6. Salib JY, Michael HN, El Nogoumy SI. New lactoyl glycoside Quercetin from Melia azedarach leaves. Chem. Nat. Compounds 2008; 44: 13-15.

7. Merra PS, and Kalidhar SB. Phytochemical investigation of Melia azedarach leaves. J. Med. Aromatic Plant Sci 2003; 25: 397-399.

8. Nyunja ARO, Erwin B, Onyango JC. The Kakamega forest medicinal plants resources and their utilization by the adjacent Luhya community. Int J Trop Med 2009; 4(3): 82-90.

9. Fernando MR, Wickramasinghe SMDN, Thabrew MI, Karunanayaka EH. A preliminary investigation of the possible hypoglycaemic activity of Asteracanthus Iongifolia. J Ethnopharmacol 1989; 27: 7-14.

10. Gilani $A H$, Ghayur MN, Saify ZS, Ahmed SP, Choudhary MI, Khalid A. Presence of cholinomimetic and acetylcholinesterase inhibitory constituents in betel nut. Life Sci 2004; 75: 2377-2389.

11. Guide for the Humane Care and Use of Laboratory Animals, National Research Council, NIH Publication No. 86-23, Washington, D.C., revised 2011

12. OECD Guidelines for the Testing of Chemicals (No. 407, Section 4: Health Effects) Repeated Dose 28-Day Oral Toxicity in Rodents, 27 July 1995.

13. Sofowora A. Medicinal Plants and Traditional Medicine in Africa. 2nd Edn., Spectrum Books Ltd., Ibadan, Nigeria, ISBN-13: 9782462195, 1993; p 289

14. Hodgkinson A, Williams A. An Improved colorimetric procedure for urine oxalate urine. Clin. Clim. Acta 1972; 36: 127-132. 
15. Gindler EM, Heth DA. Colorimetric determination with bound "calmagite" of magnesium in human serum. Clin Chem 1971: 17: 662-664.

16. Fossati P, Prencipe L, Berti G. Use of 3, 5-dichloro-2hydroxybenzenesulfonic acid/4-aminophenazone chromogenic system in direct enzymic assay of uric acid in serum and urine. Clinical Chem 1980; 26 : 227-231.

17. Afonne OJ., Orisakwe OE, Dioka CE, Obi E, Ezejiofor T, Asomugha L. Ukoha U. Effects of rinbacin extract on rat kidney. Bio. Pharm Bull 2002; 25: $1022-$ 1025.

18. Tisselius HG. Solution Chemistry of Supersaturation. In: Kidney Stones: Medical and Surgical Management, Coe FL, Favus MJ, Pak CY, Parks JH, Preminger GM (Eds). Lippincott Raven, Philadelphia, 1996; 33-64.

19. Selvam $R$, Kalaiselvi $P$, Govindaraj A, Murugan VB, Kumar ASS. Effect of $A$. lanata leaf extract and Vediuppu chunnam on the urinary risk factors of calcium oxalate urolithiasis during experimental hyperoxaluria. Pharma Res 2001; 43: 89-93.
20. Bashir S, Gilani AH. Antiurolithiatic effect of Bergenia ligulata rhizome: An explanation of the underlying mechanisms. J Ethnopharmacol 2009; 122: 10616.

21. Williams HE, Wandzilak TR. Oxalate synthesis, transport and the hyperoxaluric syndromes. J Urol 1989; 141: 742-749.

22. Pareta SK., Patra KC, Mazumder PM, Sasmal D. Establishing the Principle of Herbal Therapy for Antiurolithiatic Activity: A Review. J Pharmacol Toxicol 2011; 6: 321-332.

23. Vishnukanta, Rana AC. Evaluation of Hydroalcoholic Extract of Melia Azedarach Linn Roots for Analgesic and Anti-Inflammatory Activity. Int $\mathrm{J}$ Phytomed 2010; 2: 341-344.

24. Ramya S, Jepachanderamohan PJ, Alaguchamy N, Kalayanasundaram $M$, Jayakumararaj $R$. In Vitro Antibacterial Prospective of Crude Leaf Extracts of Melia azedarach Linn. against selected bacterial strains. Ethnobot Leaflets 13: 254-58. 2009. 